\title{
Effects of Ethyl Adenosine-5'-Garboxylate on the Heart and Coronary Circulation
}

\author{
Shoichi Imai, M.D., Ph.D., Takeshi Otori, M.D., Ph.D., Keisuke \\ Takeda, Ph.D., Yumi Katano, Ph.D., and Daijiro Horin, Ph.D.
}

\section{SUMmaRY}

Using the canine heart-lung preparation supported by a donor, the effects of ethyl adenosine- $5^{\prime}$-carboxylate (EAC) on the heart and coronary circulation were studied and compared with those of adenosine. EAC produced qualitatively similar effects to adenosine in this preparation. Aminophylline inhibited the effects of EAC as well as those of adenosine. Dipyridamole did not potentiate the effects of EAC, while it produced a definite potentiation of the effects of adenosine.

\section{Additional Indexing Words:}

Adenosine Canine heart-lung preparation with a donor Coronary circulation Myocardial redox potential Cardiac function Aminophylline Dipyridamole

$I^{\mathrm{T}}$ $\mathrm{T}$ is now fairly well established that adenosine plays an important role as a physiological regulator of the coronary circulation. In an attempt to find out an orally-active adenosine analog with a longer duration of action, ethyl adenosine-5'-carboxylate $\mathrm{HCl}$ (EAC) (A-40557) (Fig. 1) was synthesized in the Abbott Laboratories, North Chicago, U.S.A. In this paper, the effects of EAG on the heart and coronary circulation will be described and compared with those of adenosine.

\section{Materials and Methods}

Experiments were performed on the canine heart-lung preparation supported by a donor (HLP $\bar{c}$ donor). The general scheme of the preparation is depicted in Fig. 2. In all 24 experiments were performed. Mongrel dogs of either sex, weighing between 5 and $14.0 \mathrm{Kg}$ were anesthetized with sodium pentobarbital $(35 \mathrm{mg} / \mathrm{Kg}$ ) administered intraperitoneally. Under artificial respiration, the chest was opened by midsternal incision. Arterial cannula was inserted via brachiocephalic artery into the aorta and the venous cannula was inserted into the superior caval vein. All the other vessels were ligated. Blood pumped out from the left ventricle goes via arterial cannula into an extracorporeal circulation consisted of a Windkessel, a

From the Department of Pharmacology, Niigata University School of Medicine, Niigata 951, Japan.

Received for publication August 27, 1974. 


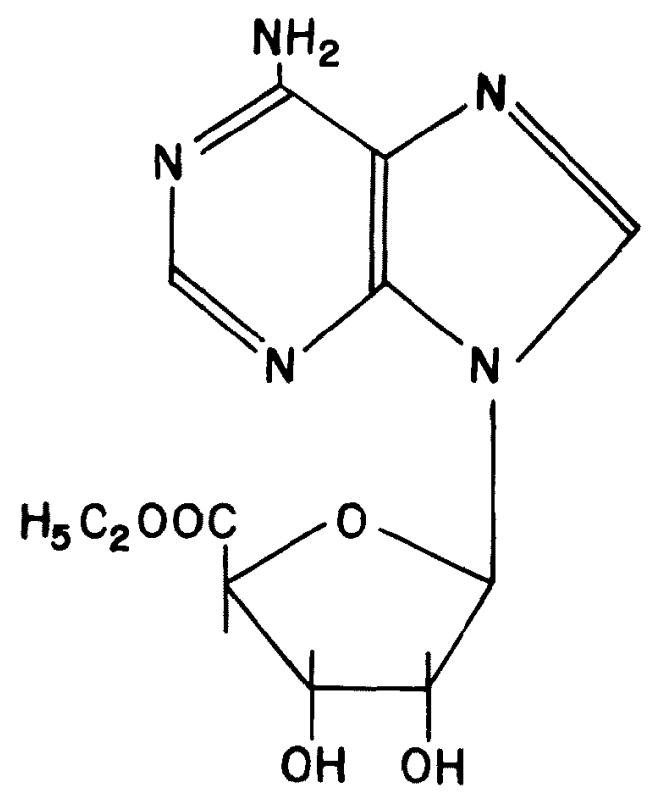

Fig. 1. Chemical structure of ethyl adenosine-5'-carboxylate.

Starling pneumatic resistance, a spiral warmer and a venous reservoir, from which the blood passes back via venous cannula to the right heart. Systemic cardiac output was measured with an electromagnetic flowmeter (Nihon Kohden MF-26) equipped with a cannulating-type probe $(6 \mathrm{~mm} \phi)$ placed between the pneumatic resistance and the spiral warmer and the arterial pressure was measured with an electronic manometer (Nihon Kohden MPU-0.5) connected to a side arm of the arterial cannula. The level of the blood in the venous reservoir was kept constant at $10 \mathrm{~cm}$ above the right atrium throughout the course of the experiment, and the venous return was adjusted to $350-450 \mathrm{ml} / \mathrm{min}$ by a screw clamp placed around the rubber tubing connecting the venous reservoir with the venous cannula. The right atrial pressure was measured with another electronic manometer (Nihon Kohden LPU-0.1). To measure the coronary blood flow, a Morawitz cannula was introduced via right atrium into the coronary sinus and the outflowing blood was led into another extracorporeal circuit composed of an electromagnetic flowmeter with a cannulating type flow-probe $(2 \mathrm{~mm} \phi)$, which measured the coronary blood flow, and an oximeter (Kipp and Zonen C. C. oximeter MO3) placed parallel to the flowmeter, to which the blood was sent by a peristaltic pump at a rate of $10 \mathrm{ml} / \mathrm{min}$ and which recorded the oxygen saturation of the blood continuously. The combined blood was, then, sent to the femoral vein of another large dog, the donor, and the fresh arterial blood from the femoral artery of the donor was pumped back to the venous reservoir of the HLP. In the usual HLP the coronary blood flow did not remain constant, but increased steadily, usually amounting to a value of more than $150 \mathrm{ml} / \mathrm{min} / 100 \mathrm{Gm}$ heart in the course of 2-3 hours and the responsiveness of the coronary artery was completely lost under this condition. Support by a donor completely eliminated this gradual deterioration of the preparation and the 


\section{HLP $\bar{c}$ donor}

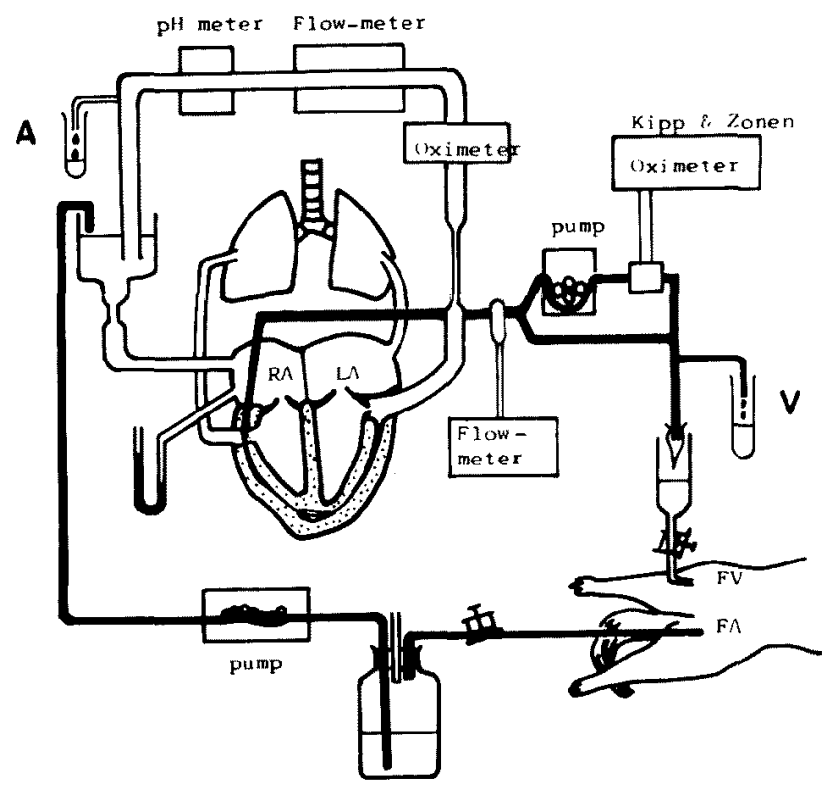

Fig. 2. General scheme of the canine heart-lung preparation supported by a donor (HLP $\bar{c}$ donor). The left upper half represents the usual heartlung preparation. A Morawitz cannula was introduced via right atrium into the coronary sinus. The outflowing blood was sent to an extracorporeal circuit composed of a flow-meter and an oximeter placed parallel to each other and passed on to the femoral vein of another large dog, the donor. The fresh arterial blood from the femal artery of the donor was pumped back to the venus reservoir of the heart-lung preparation.

coronary blood flow was kept constant at a low level for more than 8 hours.

The heart rate was calculated from ECG records (standard limb lead II). It was also recorded continuously with a cardiotachometer (Nihon Kohden RT-5). All the recordings were displayed on linearly recording ink-writing oscillograph (Watanabe Instruments WTR 281) and on an ink-jet oscillograph (Elema Schoenander Mingograph 800).

The blood needed for this preparation was obtained from other dogs under thiopental anesthesia $(20 \mathrm{mg} / \mathrm{Kg}$ i.v.). Prior to the withdrawal of the blood heparin sodium was injected to the animals $(500 \mathrm{u} / \mathrm{Kg})$, and $5,000 \mathrm{u}$ of heparin was added to each $1 \mathrm{~L}$ of blood after withdrawal. Just before use $500 \mathrm{mg}$ of glucose was added to $1 \mathrm{~L}$ of blood. Since the experiments usually lasted for more than 8 hours, a mixture of heparin $(200 \mathrm{u} / \mathrm{ml})$ and glucose $(2 \mathrm{Gm} / 15 \mathrm{ml})$ was continuously infused to the venous reservoir of the HLP at a rate of $5 \mathrm{ml} / \mathrm{hr}$, to prevent the clotting and to maintain the blood sugar at a constant level.

Donor dogs were anesthetized with a mixture of $45 \mathrm{mg} / \mathrm{Kg}$ of $\alpha$-chloralose and $450 \mathrm{mg} / \mathrm{Kg}$ of urethane administered intravenously $20 \mathrm{~min}$ after premedication of the animals with $1.5 \mathrm{mg} / \mathrm{Kg}$ of morphine hydrochloride given subcutaneously. 
Every 2 hours $100 \mathrm{u} / \mathrm{Kg}$ of heparin sodium was injected to the donor.

To obtain some information about the metabolic effects of EAC and adenosine, the effects of these substances on the myocardial redox potential $(\Delta \mathrm{Eh})$ were examined.

The myocardial redox potential $(\Delta \mathrm{Eh})$ was calculated as veno-arterial difference of the redox potential of the coronary blood. The redox potential of the coronary blood was calculated using the following equation: ${ }^{51}$ Eh $=-204-30.7$ $\log$ Lactate/Pyruvate.

For the determination of the blood lactate and pyruvate, blood samples were withdrawn at 2 places designated as $\mathrm{A}$ and $\mathrm{V}$ in Fig. 2. Two volumes of $6.5 \%$ perchloric acid (PCA) was added to the blood samples to precipitate the protein and the blood was centrifuged with a refrigerated centrifuge for $15 \mathrm{~min}$ at $13,000 \mathrm{~g}$. The pyruvic acid determinations were conducted in the following way: $0.5 \mathrm{ml}$ of $1.5 \mathrm{M}$ Tris (hydroxymethyl) aminomethane base (Tris) (Boehringer Manheim) solution was added to $2.0 \mathrm{ml}$ of the protein-free extract and well mixed. After adding $0.5 \mathrm{ml}$ of $0.64 \mathrm{mM}$ - $-\mathrm{NADH}\left(\mathrm{Na}_{2}\right.$ salt, Kyowa Hakko Kogyo) in $1.5 \mathrm{M}$ Tris, the optical density was read at $340 \mathrm{~nm}\left(\mathrm{OD}_{340}\right)$ using a double-beam spectrophotometer (Hitachi Model 124). Then, $0.05 \mathrm{ml}$ of lactic dehydrogenase $(0.4$ $\mathrm{mg} / \mathrm{ml}$ suspension in $\left(\mathrm{NH}_{4}\right)_{2} \mathrm{SO}_{4}$, Sigma Chemicals) was added and the resulting changes in the $\mathrm{OD}_{340}$ was followed until a steady minimum value was obtained. From the difference in the $\mathrm{OD}_{\mathbf{3 4 0}}\left(\Delta \mathrm{OD}_{340}\right)$, the pyruvate content was calculated using the following equation: pyruvate $(\mu \mathrm{M} / \mathrm{ml}$ of blood $)=0.72 \times \Delta \mathrm{OD}_{340}$. Determination of lactic acid was conducted in the following way: $1.0 \mathrm{ml}$ of $7 \mathrm{mM}$ $\beta$-NAD (free acid, Kyowa Hakko Kogyo) in $1 \mathrm{M}$ glycine buffer ( $\mathrm{pH} 9.2$ ) with hydrazine $(0.4 \mathrm{M})$ and EDTA $(5 \mathrm{mM}), 2.0 \mathrm{ml}$ of redistilled $\mathrm{H}_{2} \mathrm{O}$ and $0.05 \mathrm{ml}$ of lactic dehydrogenase (same as above) were poured into test tubes and well mixed. Then, $0.2 \mathrm{ml}$ of protein-free extract was added to $2.8 \mathrm{ml}$ of this mixture and incubated for $1 \mathrm{hr}$ at $37^{\circ} \mathrm{C}$. After incubation the OD was read at $340 \mathrm{~nm}$. The lactate content of the blood was calculated as follows: Lactate content $(\mu \mathrm{M} / \mathrm{ml}$ of blood) $=\mathrm{OD}_{340} \times 7.25$. Drugs used were: adenosine (Nutritional Biochemicals), dipyridamole (Persantin, Boehringer), and aminophylline (Neophylline, Eizai). Ethyl adenosine- $5^{\prime}$-carboxylate $\mathrm{HCl}$ (EAC), adenosine-5'-carboxylic acid and inosine-5'-carboxylic acid were kindly supplied by Mitsubishi Yuka Pharmaceutical Company, Tokyo, Japan. Unless otherwise indicated, drugs were injected into the rubber tubing leading to the venous cannula of the HLP.

\section{Results}

\section{Effects of $E A C$ and adenosine on the heart and coronary circulation}

In doses above $30-50 \mu \mathrm{g}, \mathrm{EAC}$ produced an increase in the coronary flow associated with only a slight negative inotropic and chronotropic effect. Fig. 3 illustrates the effects of $100 \mu \mathrm{g}$ of EAC on the HLP $\overline{\mathrm{c}}$ donor. A marked increase in the coronary flow (a rapid transient increase followed by a sustained phase) and a slight decrease in the heart rate can be seen from this figure. There was a slight rise of the right atrial pressure associated with a slight decrease in the systemic cardiac output, indicating that EAC produced a nega- 


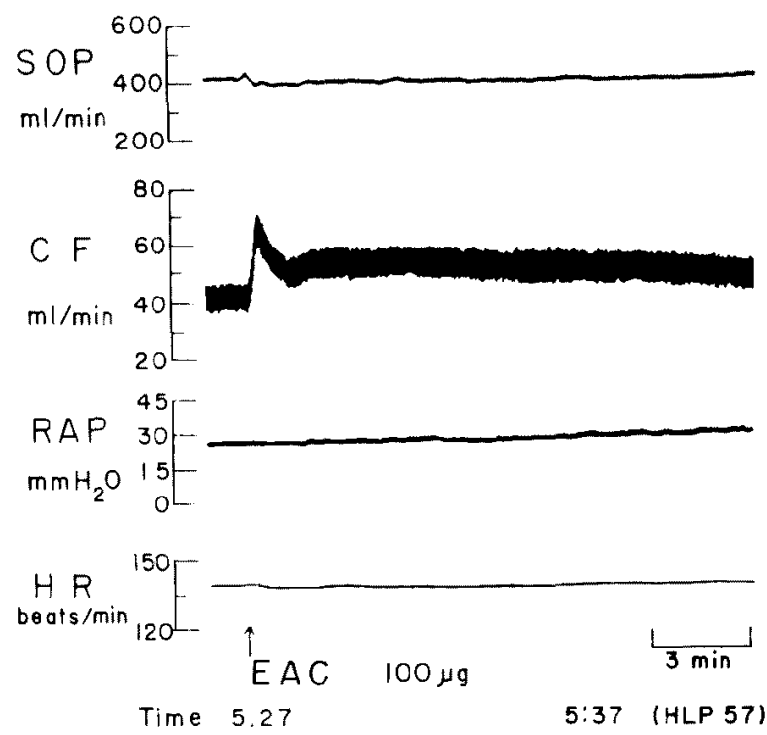

Fig. 3. Effects of ethyl adenosine-5'-carboxylate (EAC) on the canine heart-lung preparation supported by a donor. Tracings are from top to bottom: systemic cardiac output (SOP), coronary blood flow (CF), right atrial pressure (RAP), and heart rate (HR). EAC was injected as a single shot into the rubber tubing leading to the venous cannula over $10 \mathrm{sec}$.

tive inotropic effect on this preparation, although the effect was minimal.

Adenosine in doses above 1-3 mg produced qualitatively similar effects in this preparation, except that the decrease in the heart rate was more definite and the duration of action was much shorter (Fig. 4). As is demonstrated in this figure, the effect of adenosine was much weaker when the substance was injected into the rubber tubing leading to the venous cannula (venous side of the preparation) than when it was injected into the left atrium (arterial side of the preparation). To obtain an increase in the coronary flow of the same magnitude 20 times or more of adenosine was necessary when it was given to the venous side than to the arterial side. In contrast, EAC produced almost the same increase in the coronary flow irrespective of whether it was given to the arterial side or to the venous side (Fig. 8).

As is illustrated in Fig. 5 myocardial oxygen consumption, a major determinant of the coronary blood flow, remained unchanged after EAC, indicating that the substance exerted a direct dilatatory effect on the coronary vasculature. Adenosine produced no change in the myocardial oxygen consumption, either (Fig. 5).

In order to get some information about the metabolic changes to be induced by EAC and adenosine in the heart, the effects of these substances 
$4 \mathrm{~min}$

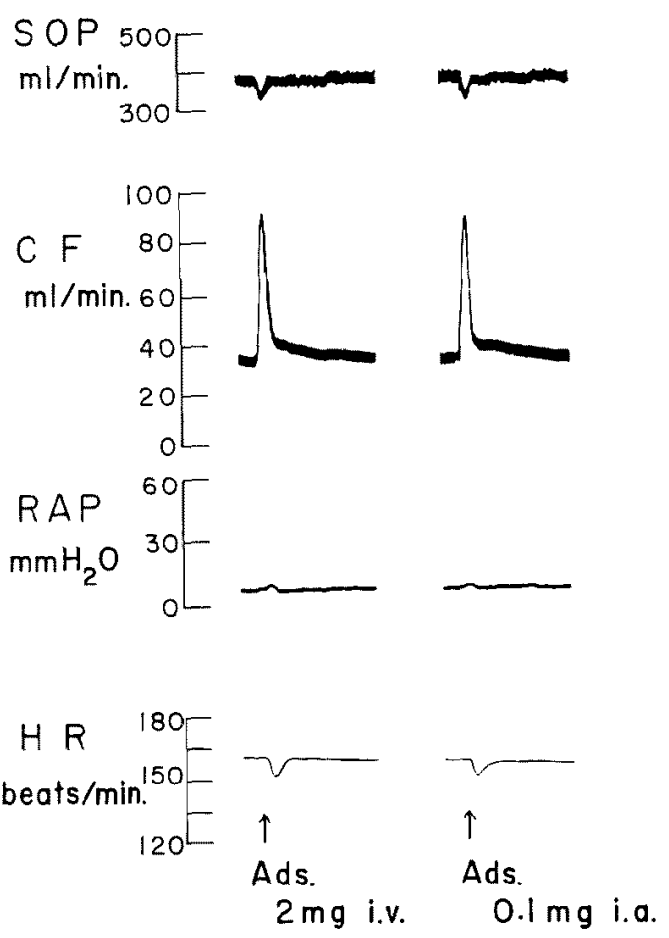

Fig. 4. Effects of adenosine (Ads) on the HLP $\overrightarrow{\mathbf{c}}$ donor. Tracings are from top to bottom: systemic cardiac output (SOP), coronary blood flow (CF), right atrial pressure (RAP), and heart rate (HR). Adenosine was injected either into the rubber tubing leading to the venous cannula (designated as i.v.) or injected into the left atrium (designated as i.a.) as a single shot over $10 \mathrm{sec}$.

on the myocardial redox potential ( $\triangle \mathrm{Eh}$ ) were studied. In Fig. 6 is depicted the effect of EAC, in comparison with that of adenosine. As can be seen from this figure, both EAC and adenosine produced no significant change in $\Delta \mathrm{Eh}$.

Antagonistic effect of aminophylline to $E A C$ and adenosine

According to DeGubareff and Sleator ${ }^{4)}$, and Afonso"), the effects of adenine nucleotides as well as adenosine on the heart and coronary circulation can be specifically antagonized by methylaxanthines, e.g. by aminophylline. In view of the similarity of the chemical structure and of the mode of action of EAC to adenosine, it was of interest to examine whether aminophylline could antagonize the effect of EAC or not. As depicted in Fig. 7, $10 \mathrm{~min}$ after $5 \mathrm{mg}$ of aminophylline, when the effects of this substance subsided com- 


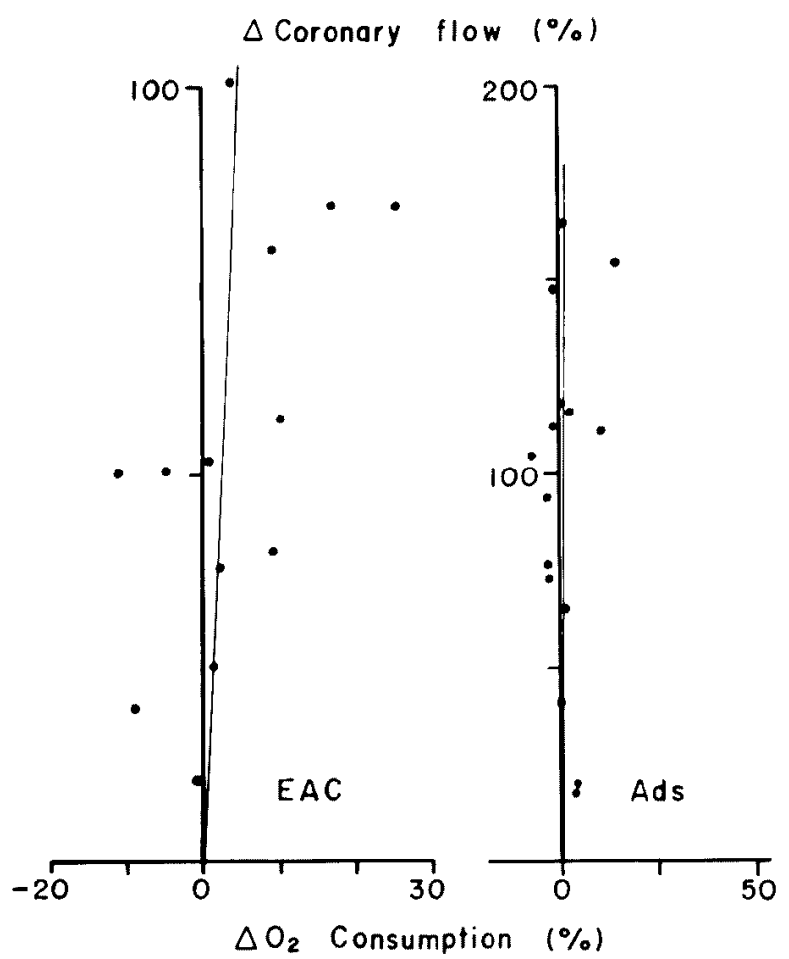

Fig. 5. Effects of ethyl adenosine-5'-carboxylate (EAC) and adenosine (Ads) on the relation between the myocardial oxygen consumption and the coronary flow. The abscissa: changes in the myocardial oxygen consumption expressed as percent of the initial value. The ordinate: changes in the coronary blood flow expressed as percent of the initial value. EAC was injected as a single shot over $10 \mathrm{sec}$ in a dose of $50-100 \mathrm{~kg}$. Adenosine was infused continuously at a rate of $3 \mathrm{mg} / \mathrm{min}$.

pletely, the effect of EAC as well as that of adenosine was found to be much reduced.

\section{Lack of potentiation of the effect of EAC by dipyridamole}

Some recently-introduced coronary vasodilators, e.g. dipyridamole, lidoflazine, hexobendine, and dilazep, produce a potentiation of the effect of adenosine, ${ }^{21,31,6(, 9), 12), 13,15)}$ probably through an inhibition of the uptake of the substance into various tissues, notably the lung and the heart. $\left.{ }^{2,}, 7\right), 81,11,12$, EAC does not belong to this group of vasodilators; there was no potentiation of the effects of adenosine after EAC (Fig. 8). Moreover, in spite of its structural similarity to adenosine, the effects of EAC was not potentiated by adenosine-potentiating agents. In the present experiment dipyridamole was chosen as an adenosine-potentiating agent. As depicted in Fig. 9, $30 \mu \mathrm{g}$ 
EAC
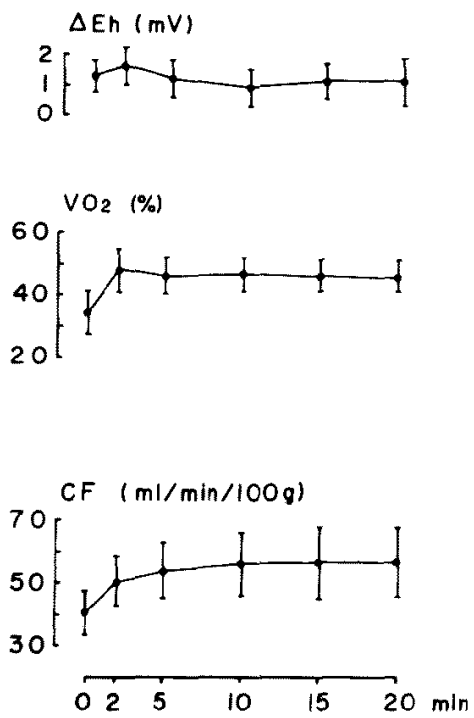

Adenosine
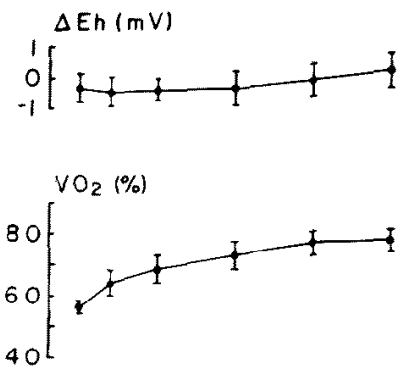

CF $(\mathrm{ml} / \mathrm{min} / 100 \mathrm{~g})$

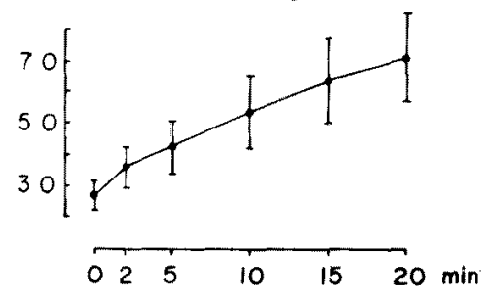

Fig. 6. Effects of ethyl adenosine $-5^{\prime}$-carboxylate (EAC) and adenosine on the myocardial redox potential ( $\Delta \mathrm{Eh}$ ) and the oxygen saturation of the coronary sinus blood $\left(\mathrm{VO}_{2}\right)$. To give some idea about the temporal relation of the metabolic effects to the functional states of the preparation, the changes in the coronary flow are also depicted in this figure. EAC (50-100 $\mu \mathrm{g})$ was injected as a single shot over $10 \mathrm{sec}$ into the rubber tubing leading to the venous cannula $(n=10)$. Ads was infused continuously via the same route at a rate of $3 \mathrm{mg} / \mathrm{min}(n=6)$. Each point represents the mean \pm S.E.

of dipyridamole, which by itself produced a slight increase in the coronary flow, did not potentiate the effects of EAC, while it produced a definite potentiation of the effects of adenosine, especially when it was administered to the venous side of the preparation.

Effects of adenosine-5'-carboxylic acid and inosine-5'-carboxylic acid

According to Merits and Anderson, ${ }^{101} \mathrm{EAC}$ undergoes hydrolysis and deamination once it is within the body to become adenosine-5'-carboxylic acid and inosine-5'-carboxylic acid. Therefore, the effects of these 2 compounds on the heart and coronary were also studied. Both of these 2 substances, even in doses as high as $3 \mathrm{mg}$, did not produce any remarkable effect on HLP $\overline{\mathrm{c}}$ donor.

\section{Discussion}

Experiments performed with HLP $\overline{\mathrm{c}}$ donor clearly demonstrated that 


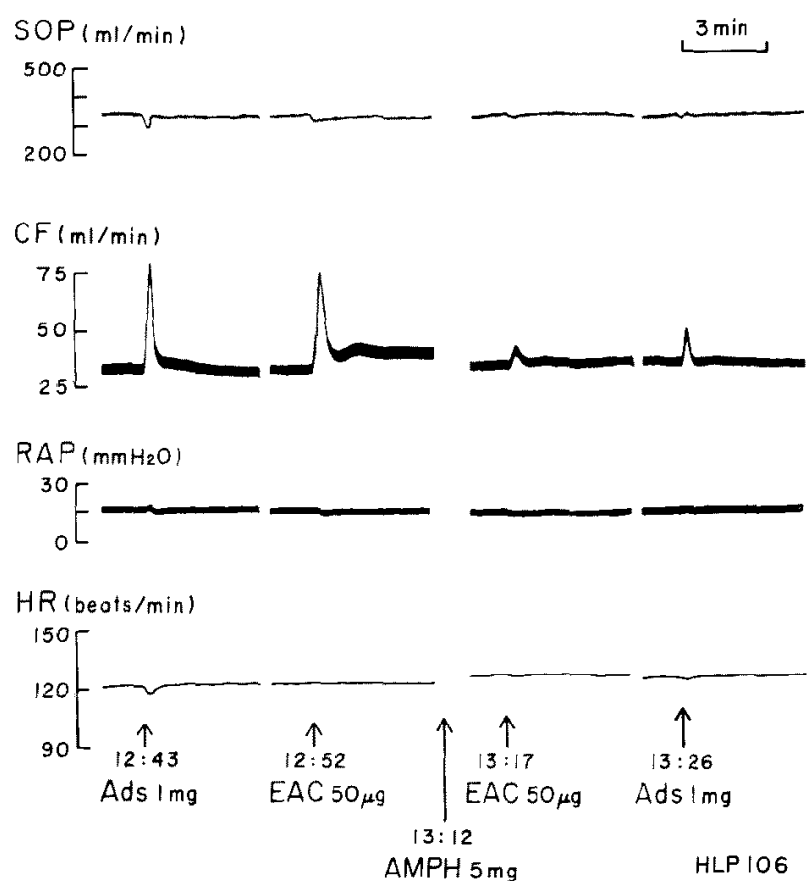

Fig. 7. Inhibition of the effects of ethyl adenosine-5'-carboxylate (EAC) and adenosine (Ads) by aminophylline (AMPH). Abbreviations are the same as in Fig. 2 .
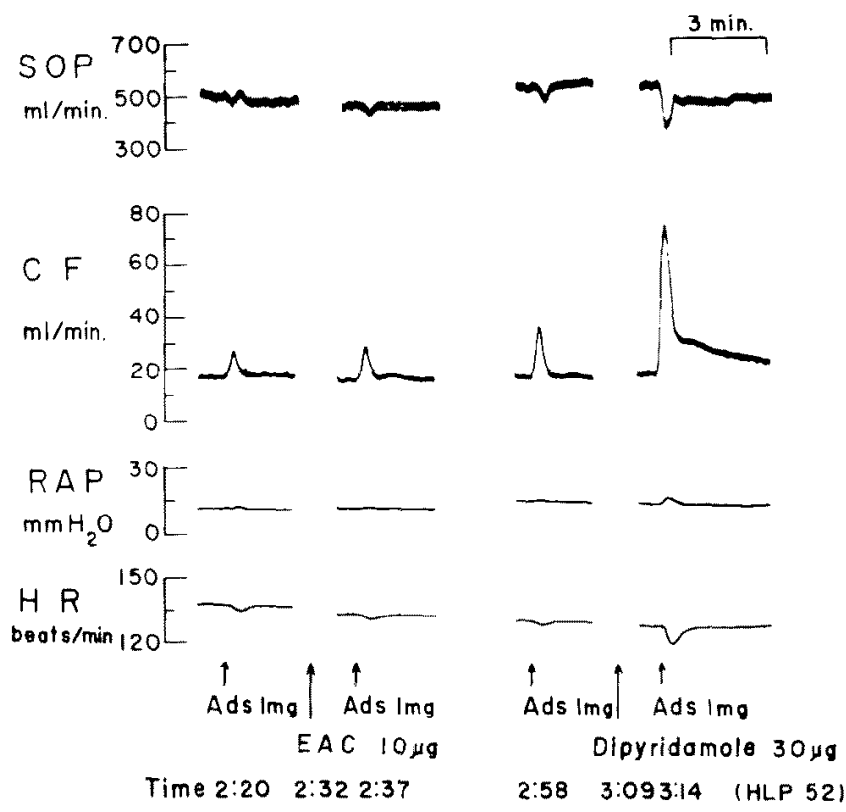

Fig, 8. Lack of potentiation of the effect of adenosine (Ads) by ethyl adenosine-5'-carboxylate (EAC). Abbreviations are the same as in Fig. 2. For comparison the adenosine potentiation by dipyridamole is shown in the figure. 


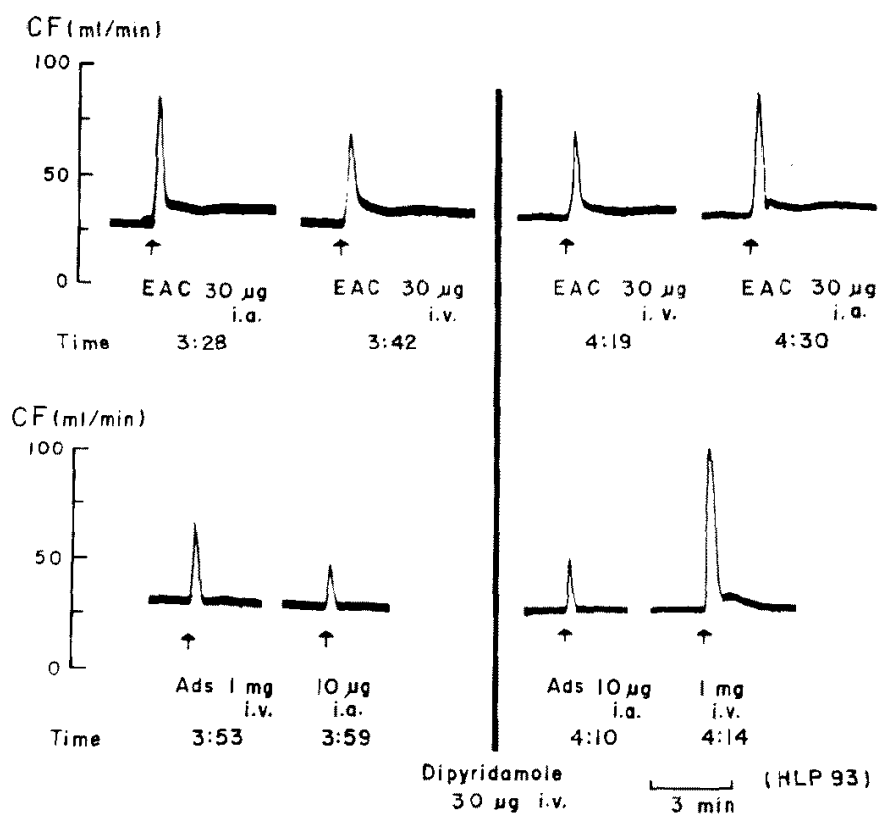

Fig. 9. Lack of potentiation of the effects of ethyl adenosine- 5 -carboxylate (EAC) by dipyridamole. EAC was injected via 2 routes: (1) Injection into the rubber tubing leading to the venous cannula (i.v.) and (2) injection into the left atrium (i.a.). The same dose of dipyridamole produced a definite potentiation of the effect of adenosine (Ads), especially when Ads was injected into the rubber tubing leading to the venous cannula (i.v.). Abbreviations used are: coronary blood flow (CF).

the effects of EAC, an adenosine analog, on the heart and coronary circulation are qualitatively similar to those of adenosine, except that the duration of action was rather long.

Since aminophylline, a specific antagonist of adenosine and adenine nucleotides, ${ }^{14}$ inhibited the effect of EAC as well as that of adenosine, it may be inferred that EAC produces its effects through activation of the receptor through activation of which adenosine and adenine nucleotides produce their effects.

Sano et $\mathrm{al}^{13)}$ demonstrated in the dog that much larger amount of adenosine was needed to produce an increase of the coronary flow of the same magnitude when it was given to the animal by the venous route than by close arterial injection. In the present experiment, 20 times or more of adenosine was necessary to produce the same increase in the coronary flow when it was given to the venous side of the preparation than when it was given to the arterial side, in agreement with the results obtained by Sano et al ${ }^{13}$. Thus $95 \%$ of this substance disappeared during a single passage through the lung. 
In contrast, EAC produced an increase in the coronary flow of nearly the same magnitude, irrespective of whether it was given to the arterial side or the venous side, indicating that the lung did not eliminate this substance so efficiently as adenosine. This may be the reason why the effect of EAC was not potentiated by dipyridamole, while the effect of adenosine was markedly potentiated; the adenosine-potentiation by dipyridamole was thought to be mainly due to a blockade of elimination of this substance by the lung. ${ }^{21,11)}$ The fact that the duration of action of EAC was longer than its congener can also be explained on the same basis.

In conclusion, EAC can be classified as a substance belonging to the family of adenosine and adenine nucleotides with respect to its effects on the heart and coronary circulation. However, the presence of the esterified carboxyl group at position $5^{\prime}$ made it not so liable to elimination by the lung as its parent compound, thus making the duration of its action much longer.

\section{ACKNOWLEDGEMENT}

The authors with to express their thanks to Mr. H. Sakurai and Mr. A. Mitomi for their skillful technical assistance and for Miss S. Tase for her help in preparing the manuscript.

This work was supported by the grant from the Ministry of Education of Japan, a Japan Heart Foundation Research Grant for 1973, and Naito Research Grant for 1973.

\section{REFERENCES}

1. Afonso S: Inhibition of coronary vasodilating action of dipyridamole and adenosine by aminophylline in the dog. Circulat Res 26: 743, 1970

2. Afonso S, O'Brien GS: Mechanism of enhancement of adenosine action by dipyridamole and lidoflazine in dogs. Arch internat Pharmacodyn 194: 181, 1971

3. Bretschneider HJ, Frank A, Bernard U, Kochsiek K, Scheler F: Die Wirkung eines Pyrimidopyrimidin-derivates auf die Sauerstoffversorgung des Herzmuskels. Arzneimittel-Forsch 9 : 49,1959

4. De Gubareff T, Sleator W, Jr: Effects of caffeine on mammalian atrial muscle and its interaction with adenosine and calcium. J Pharmac exp Ther 148: 202, 1965

5. Gudbjarnason S, Heyden RO, Wendt VE, Stock TB, Bing RJ: Oxidation reduction in heart muscle. Circulation 26: 937, 1962

6. Hockerts T, Bögelmann G: Untersuchungen über die Wirkung von 2,6-Bis (diaethanolamino)-4, 8-dipiperidino-pyrimido (5,4-d) Pyrimidin auf Herz und Kreislauf. ArzneimittelForsch 9: 47, 1959

7. Hopkins SV, Goldie RG: A species difference in the uptake of adenosine by heart. Biochem Pharmac 20: 3359, 1971

8. Kolassa N, Pfleger K, Rummel W: Specificity of adenosine uptake into the heart and inhibition by dipyridamole. Eur J Pharmac 9 : 265, 1970

9. Kraupp O, Wolner E, Adler-Kastner L, Ploszczanski B, Tuisl E: Die Wirkung von N, N'- 
Dimethyl-N, $\mathrm{N}^{\prime}$-bis (3-( $3^{\prime}, 4^{\prime}, 5^{\prime}$-trimethoxy-benzoxy)-propyl)-äthylen-diamin dihydrochlorid auf den Herzstoffwechsel. Arzneimittel-Forsch 15: 1187, 1965

10. Merits I, Anderson DJ: Studies on $\left[8{ }^{14} \mathrm{C}\right]$ adenosine-5'-carboxylic acid ethyl ester. 1 . Metabolic fate in the dog, rat and mouse. Xenobiotica 3: 381, 1973

11. Pfleger K, Schöndorf H: Zur Aufklärung des Wirkungsmechanismus von Dipyridamole. Arzneimittel-Forsch 19: 97, 1969

12. Pfleger K, Volkmer I, Kolassa N: Hemmung der Aufnahme von Adenosin und Verstärkung seiner Wirkung am isolierten Warmblüterherzen durch coronarwirksame Substanzen. Arzneimittel-Forsch 19: 1972, 1969

13. Sano N, Katsuki S, Kawada M: Enhancement of coronary vasodilator action of adenosine by 1, 4-bis 3-(3,4,5-trimethoxybenzoyloxy)-propyl)-perhydro-1, 4-diazepine (Dilazep I.N.N.). Arzneimittel-Forsch 22: 1655, 1972

14. Scholtholt J, Nitz RE, Schraven E: On the mechanism of the antagonistic action of xanthine derivatives against adenosine and coronary vasodialators. Arzneimittel-Forsch 22: 1255, 1972

15. Stafford A: Potentiation of adenosine and the adenine nucleotides by dipyridamole. Br J Pharmac 28: 218, 1966 